\title{
Detection of blood and DNA traces after thermal exposure: a critical appraisal
}

\author{
Navneet Ateriya ${ }^{1}$ (D) $\cdot$ Rutwik Shedge ${ }^{1} \cdot$ Ashish Saraf $^{1} \cdot$ Tanuj Kanchan $^{1}$ \\ Received: 14 March 2019 / Revised: 14 March 2019 / Accepted: 22 May 2019 / Published online: 28 May 2019 \\ (C) Springer-Verlag GmbH Germany, part of Springer Nature 2019
}

\section{Dear Editor,}

We would like to congratulate the authors for an informative article titled Detection of blood and DNA traces after thermal exposure [1]. The authors exposed different objects to three different temperature ranges of 300,700 , and $1000{ }^{\circ} \mathrm{C}$, and successfully documented influence of heat on blood traces by the use of luminal. Their conclusion that DNA can be profiled even at such high temperature has wide forensic implications. We however, seek certain elaborations for a better understanding of this very significant research.

The authors used three different corpses for collection of the blood that was applied over different objects. Could blood from a single cadaver have been used to ensure homogeneity? Doing this might have negated the problem caused with the tile for $700{ }^{\circ} \mathrm{C}$ temperature. Was sterilization of all objects done before application of blood so as to avoid contamination? During the test fires, the objects without application of blood were arranged on a stoneware slate while the blooded samples were in a copper basin. Was there any specific reason for use of copper basin for one and stoneware slate for the other? Should copper have been used anyway, its melting point is quite near $1000{ }^{\circ} \mathrm{C}\left(1085{ }^{\circ} \mathrm{C}\right.$ to be exact)? Also, copper is a known interferent of blood for the presumptive tests. We believe that use of interferents could have been avoided for improving specificity of the results.

Authors have stated that they used only a few random samples that were heated at $300^{\circ} \mathrm{C}$ for DNA analysis. However in figure 4, the bar chart shows results for all the samples [1].

Navneet Ateriya

dr.navneet06@gmail.com

1 Department of Forensic Medicine and Toxicology, All India Institute of Medical Sciences, Jodhpur 342 005, India
Similarly, authors mentioned that a complete, single DNA pattern was identified on $60 \%$ test objects exposed to $1000{ }^{\circ} \mathrm{C}$, but table 1 shows the same in only 4 cases $(36.36 \%)$ [1]. We would appreciate clarifications, if any in this regard.

The authors may provide the details of the duration of cooling for the test objects as cooling up to desired temperature can vary in different materials. As far as DNA sampling is concerned, only one swab was taken every time. Possibility of using wet and dry swab method can be employed for better results in similar studies. Although the test objects with blood and without blood were separated from each other, they could have been individually wrapped to reduce any potential contamination. All test objects of one temperature were subjected to flashover simulator at the same time during the test, although separated from each other. Specific partitions to separate the samples could have further reduced the chances of contamination.

\section{Compliance with ethical standards}

Conflict of interest The authors declare that they have no conflict of interest.

\section{Reference}

1. Klein A, Krebs O, Gehl A, Morgner J, Reeger L, Augustin C, Edler $\mathrm{C}$ (2017) Detection of blood and DNA traces after thermal exposure. Int J Legal Med 132(4):1025-1033

Publisher's note Springer Nature remains neutral with regard to jurisdictional claims in published maps and institutional affiliations. 